
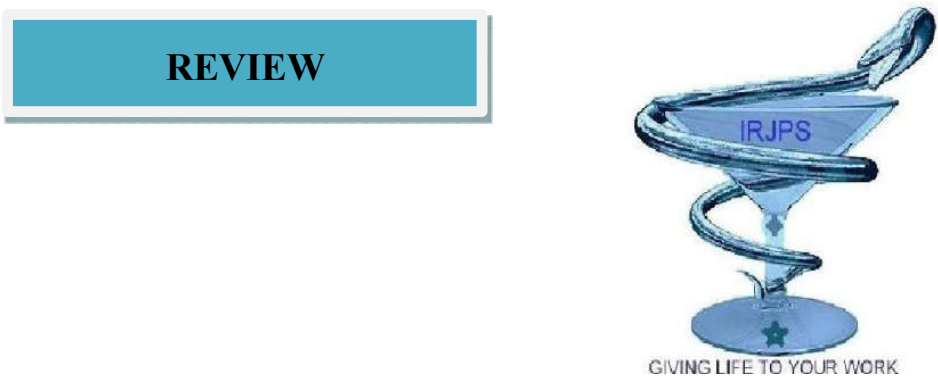

\title{
LUBRICANTS: SIGNIFICANCE IN TABLET DEVELOPMENT PROCESS
}

\author{
Pallavi V. Pawar*, Sachin A. Ahire, Ramhari Shinde \\ RKDF School of Pharmaceutical Sciences, NH-12, Jatkhedi, Hoshangabad Road, Bhopal- 462026,(M.P.)
}

\section{Submitted on: 18.05.18; $\quad$ Revised on: 15.06.18; $\quad$ Accepted on: 25.06.18}

\begin{abstract}
:
Lubrication plays an important role in efficient manufacturing of pharmaceutical solid dosage forms; lubricants are necessary ingredients in vigorous formulations to achieve this. Lubricants are commonly added additives to many pharmaceutical solid formulations. Following compression, a tablet must be ejected out of the tablet press die. Lubricants reduce the friction between the tablet and the die metal surface which decreases the ejection force and helps to make sure that the tablet is totally ejected. High friction during Compression can cause a series of problems, including inadequate tablet quality from capping or even fragmentation during ejection Introduction In this review, the basic conditions on lubrication is introduced, in which the relationships between lubrication and friction/adhesion forces are discussed. Then, the application of lubrication in the growth of pharmaceutical products and manufacturing processes is discussed with an emphasis on magnesium stearate. In particular, the effect of its hydration state (anhydrate, monohydrate, di-hydrate, and tri-hydrate) and its fine particles characteristics on lubrication efficiency, as well as product and process performance is summarized. In addition, the impact of lubrication on the dynamics of compaction/compression processes and on the mechanical properties of compacts/tablets is presented. Furthermore, the online monitoring of magnesium stearate in a blending process is briefly mentioned. Finally, the chemical compatibility of active pharmaceutical ingredient (API) with magnesium stearate and its reactive impurities is reviewed with examples from the literature illustrating the various reaction mechanisms involved.
\end{abstract}

KEYWORDS: Lubricants, Compression, Friction, magnesium stearate, Tablets

Corresponding Author: Pallavi V. Pawar E-Mail: pallpawar@rediffmail.com
Indian Research Journal of Pharmacy and Science; 17(2018)1491-1499; Journal Home Page: https://www.irjps.in DOI: 10.21276/irjps.2018.5.2.12 


\section{INTRODUCTION:}

Lubricants are commonly added excipients to many pharmaceutical tablet formulations. Following compression, a tablet must be ejected out of the tablet press die. Lubricants reduce the friction between the tablet and the die metal surface which reduces the ejection force and helps to ensure that the tablet is completely ejected. High friction during tableting can cause a series of problems, including inadequate tablet quality from capping or even fragmentation during ejection ${ }^{[1,2]}$. One class of functional excipients that are essential in most solid oral dosage forms is "lubricants". ${ }^{3]}$

There are two main mechanisms by which lubrication is achieved:

1) Fluid lubrication.

2) Boundary lubrication.

In fluid lubrication, the lubrication forms a thin, continuous fluid layer between the tablet and metal dies surface. Fluid lubricants are seldom used in tablet formulations. However, liquid paraffin has been used in formulations for effervescent tablets. Lubricants utilizing the boundary lubrication mechanism are the most common ${ }^{[3]}$.

In boundary lubrication, the sliding surfaces are separated by a very thin film of lubricant. The nature of the tablet and die surface properties will thus frictional forces present.

There are six categories of boundary lubricants commonly used for pharmaceutical tableting:

(i) Metallic salts of fatty acids,

(ii) Fatty acids, hydrocarbons and fatty alcohols,

(iii) Fatty acid esters.

(iv) Alkyl sulfates,

(v) Polymers, and

(vi) Inorganic materials

Magnesium stearate, a metallic salt boundary lubricant, is probably the most commonly used lubricant for pharmaceutical tableting, it is comparatively cheap, provides high lubrication, has a high melting point and is chemically stable ${ }^{[5]}$.
1.2 Common lubricants and classification are summarized their

\subsubsection{Lubricant classification ${ }^{[1,6,7]}$}

\section{A. Metallic salts of fatty acids :}

Magnesium stearate, aluminum stearate, calcium stearate, sodium stearate, zinc stearate.

B. Fatty acids, hydrocarbons and fatty alcohols :

Stearic acid, decanoic, dodecanoic, docosanoic, octadecanoic, eicosanoic

\section{Fatty acid esters :}

Sodium stearyl fumarate, sodium lauryl sulfate, magnesium lauryl sulfate,

Glyceryl behenate, dodecanoic triglyceride, samarium stearate, sucrosemonopalmitate

\section{Alkyl sulfates :}

Magnesium lauryl sulfate, sodium lauryl sulfate

\section{E. Polymers :}

PEG 4000, PEG-6000, polyoxyethylene \& p

olyoxyproprylene copolymer, polytetrafluoroethylene

\section{F. Inorganic materials :}

Magnesium silicate, aluminum silicate

As magnesium stearate is the most commonly used boundary layer lubricant, it has been the most extensively studied. It has been hypothesized that the film formed by magnesium stearate around other excipient particles could be:

(i) As a monomolecular film of magnesium stearate particles bound to the other excipient's by their polar heads.

(ii) As a monoparticulate film of magnesium stearate particles covering the surface of the other excipients, and

iii) As layers of magnesium stearate particles first filling any cavities of the other excipients before forming a continuous layer. 
The third hypothesized mechanism of first filling any cavities is the most popular. With this mechanism, magnesium stearate would improve flow by minimizing any surface irregularities of the excipients which reduces contact points between excipients, decreasing friction forces.

\subsection{Lubricant effect on flow}

Powder flow is serious during tableting as it have to flow simply and consistently into the tablet dies to ensure tablet weight uniformity and production of tablets with consistent and reproducible properties. Powder flows when gravitational forces become higher than the friction and cohesion forces that influence particle-particle interactions. Cohesive forces refer to the attraction between particles and include van der Waals' forces, capillary forces and electrostatic forces. Cohesive forces are affected by the surface properties of the particles. As boundary layer lubricants form a film around particles, these lubricants affect the cohesive forces thereby also affecting powder flow. Furthermore, friction is also affected by the surface properties of the particles. Friction acts at contact points between particles; thus, surface morphology affects friction forces. If the contact area is increased, the potential contact points are increased, thus increasing friction. Boundary layer lubricants reduce friction by reducing surface irregularities, reducing contact points between particles, and thus friction forces. The effect of lubricants on flow has been examined by numerous researchers. Changes in flowability, by the addition of magnesium stearate improved the flow of the cohesive Ibuprofen powder at all size cuts ${ }^{[7]}$.

\subsection{Effect on tablet properties}

Besides reducing friction and cohesion, lubricants may cause undesirable changes in the properties of the tablet. The presence of lubricant in a powder is thought to interfere in a destructive way with the bonding between particles during compaction, thus reducing final tablet strength. Lubricant type, concentration, method of lubrication, and the manner of incorporating the lubricant all affect the tablet compression. It is generally accepted that magnesium stearate has more negative effect on the hardness and tensile strength of the tablets with more deformable materials than brittle ones conducted a study using dibasic calcium phosphate as an example of a material that is susceptible to brittle fracture during compaction. Results showed that the tablet strength showed no change when magnesium stearate up to $3 \%$ wt was present. Other lubricants, such as stearic acid and talc, showed no effect on the interparticle bonding, and thus tablet strength, of dibasic calcium phosphate dehydrate up to $8 \%$ wt. Alternatively, when microcrystalline cellulose, an example of a plastic material, was mixed with magnesium stearate, the tablet strength was weakened significantly as the amount of added lubricant increased. Similar results were obtained when other lubricants (stearic acid, talc, and15PEG) were mixed with microcrystalline cellulose. The adverse impact of magnesium stearate on lactose and starch, excipients that also deform plastically, was also observed ${ }^{[2,8,9]}$.

Because many lubricants are hydrophobic, tablet disintegration and dissolution are often retarded by the addition of lubricant. Multiple studies have led to the theoretical conclusion that the deleterious effects observed are a cause of the combination of the large surface area and hydrophobicity of the lubricant. Many research showed that the powder form of magnesium stearate have more adverse effects on tablet hardness and disintegration than the granular form. A decrease in the magnesium stearate level from $1.7-0.85 \mathrm{mg}$ in a tablet comprised of mostly calcium phosphate dibasic reduced the disintegration time from 10 to $4.5 \mathrm{~min}$ (Bavitzetal., 1986\&Strickland et al.1956) showed that disintegration time increased substantially more for increases of magnesium stearate than other lubricants stearic acid and stearyl alcohol.

\subsection{Magnesium stearate}

Magnesium stearate, also called octadecanoic acid, magnesium salt, is a white substance, powder which becomes solid at room temperature. It has the chemical formula $\mathrm{Mg}\left(\mathrm{C}_{18} \mathrm{H}_{35} \mathrm{O}_{2}\right)_{2}$. It is a salt containing two equivalents of stearate (the anion of stearic acid) and one magnesium cation $\left(\mathrm{Mg}^{2+}\right)$. Magnesium stearate melts at about $120^{\circ} \mathrm{C}$, is not soluble in water, and is generally considered safe for human consumption at levels below $2500 \mathrm{mg} / \mathrm{kg}$ per day. In 1979, the FDA's Subcommittee on GRAS (generally recognized as 
safe) Substances (SCOGS) reported, "There is no evidence in the available information on magnesium stearate that demonstrates, or suggests reasonable grounds to suspect, a hazard to the public when they are used at levels that are now current and in the manner now practiced, or which might reasonably be expected in the future ${ }^{[11,12]}$.

Magnesium stearate is often used as a diluent in the manufacture of medical tablets, capsules and powders. In this regard, the substance is also useful, because it has lubricating properties, preventing ingredients from sticking to manufacturing equipment during the compression of chemical powders into solid tablets; magnesium stearate is the most commonly used lubricant for tablets. Studies have shown that magnesium stearate may affect the release time of the active ingredients in tablets, etc., but not that it reduces the overall bioavailability of those ingredients. food additive or pharmaceutical excipient, its E number is E470b.

Magnesium stearate is also used to bind sugar in hard candies like mints, and is a common ingredient in baby formulas. In pure powder form, the substance can be a dust explosion hazard, although this issue is effectively insignificant beyond the manufacturing plants using it.

Magnesium stearate is manufactured from both animal and vegetable oils. Some nutritional supplements specify that the magnesium stearate used is sourced from vegetables.

Magnesium stearate is a major component of "bathtub rings." When produced by soap and hard water, magnesium stearate and calcium stearate both form a white solid insoluble in water, and are collectively known as "soap scum."

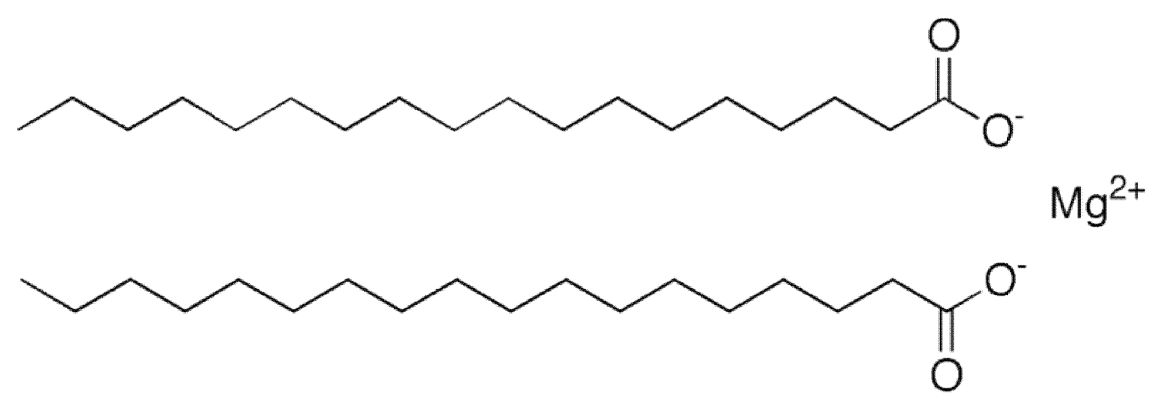

Fig. 1: Structure of magnisium stearate:

Table 1: Physicochemical properties of magnesium stearate

\begin{tabular}{|c|c|l|}
\hline S. NO. & \multicolumn{2}{|c|}{ Properties } \\
\hline 1 & Molecular formula & $\mathrm{Mg}\left(\mathrm{C}_{18} \mathrm{H}_{35} \mathrm{O}_{2}\right)_{2}$ \\
\hline 2 & Molar mass & $591.27 \mathrm{~g} / \mathrm{mol}$ \\
\hline 3 & Appearance & light white powder \\
\hline 4 & Odor & Slight \\
\hline 5 & Density & $1.026 \mathrm{~g} / \mathrm{cm}^{3}$ \\
\hline 6 & Melting point & $88.5^{\circ} \mathrm{C}, 362 \mathrm{~K}, 191{ }^{\circ} \mathrm{F}$ \\
\hline 7 & Solubility in water & $0.003 \mathrm{~g} / 100 \mathrm{ml}\left(15^{\circ} \mathrm{C}\right), 0.004 \mathrm{~g} / 100 \mathrm{ml}\left(25^{\circ} \mathrm{C}\right) 0.008 \mathrm{~g} / 100 \mathrm{ml}\left(50^{\circ} \mathrm{C}\right)$ \\
\hline 8 & Solubility & Negligible in ether and alcohol, slightly soluble in benzene \\
\hline
\end{tabular}


1.5 Magnesium stearate safety, side effects, and toxicity, problems review of studies

Stearic acid is a common fatty acid found in significant amounts in meat, poultry, fish, eggs, butter, grains, and milk products. Some websites have misleading information regarding the safety of magnesium stearate. Some of these sites claim magnesium stearate, even in as small an amount as a few milligrams. As found in dietary supplement capsules, is dangerous. There is no evidence this is true, particularly the tiny amounts found in supplements. I am not aware of any human studies that show Magnesium Stearate, in the small amounts found in capsules, has any side effects or cause any harm. There is no evidence that small amounts of stearic acid are harmful. If anyone knows of a human study that indicates magnesium stearate, in the small amounts found in capsules, when taken orally in supplement form, has shown to have harmful effects.

Much of this misinformation is posted by companies who are trying to differentiate themselves from other vitamin companies by providing products that are free of magnesium stearate, perhaps because they are not able to compete solely on the actual effectiveness of their products. If anyone tells you magnesium stearate in the extremely small amounts found in capsules is harmful, challenge them to provide you with a human study that proves their point they will not be able to. For some consumers this whole issue has become almost a psychological obsession going way beyond any logical reasoning. Some people regularly eat a piece of pie, cookie, or other sweet or junk food, or consume chocolate (which has tons of stearic acid) without any concerns, but get all worked up about insignificant amounts found in capsules. It defies logic ${ }^{[10,11]}$.

Most dietary supplement capsules have about $500 \mathrm{mg}$ of herbs or nutrients and perhaps 10 $\mathrm{mg}$ or less of magnesium stearate. Since magnesium mineral is part of the overall weight of the molecule, the amount of stearate alone is even less than $10 \mathrm{mg}$. One kilogram equals 1000 grams, and one gram equals $1000 \mathrm{mg}$. A few milligrams is an insignificant amount compared to the millions of milligrams of food we consume a day.

\subsection{Properties of a good lubricant}

1. Low Shear Strength- Want the lubricant to hear during blending, not the granules or other excipients in the formulation.

2. Able to form a "durable layer" over the surface covered.

3. Non-Toxic

4. Chemically Inert

5. Unaffected by Process Variables

6. Posses Minimal Adverse Effects on the Finished Dosage Form.

\subsection{How do lubricant works? ${ }^{[28]}$ \\ 1.7.1 Magnesium stearate}

Magnesium (and calcium) stearate exists as "plate like" crystals (or lamellae) stacked together like a deck of cards. As the blending process proceeds, plates continue to shear off and coat adjacent particles of granules, drug or other excipients. The higher the concentration of magnesium stearate used or the longer this blending continues, the more complete this coating of the adjacent particles will become. For effective lubrication, you do not need and, in fact, you do not want to coat everything too completely with the lubricant or the problems mentioned previously are likely to occur.

\section{What causes these problems?}

The hydrophobic coating interferes with "wetting" thereby leading to increases in the time required for the tablet to disintegrate and the drug to become dissolved.

Additionally, a complete coating of lubricant may affect tablet hardness by interfering with the interparticle bonding required by formulations where tablets are formed with components that bond by plastic deformation.

Tablets formed by brittle fracture are less affected because brittle fracture produces clean "unlubricated" sites where bonding can occur during compression. 
Wet granulation formulations are also less affected (than direct compression formulations) since significant clean surfaces are formed during compression as the granules deform with shear to provide bonding sites.

The use of Magnesium Stearate as a lubricant has further complications in that a variety of commercial samples have been known to exhibit significant batch-to-batch variation in their lubricant properties. Three factors have been determined to be mainly responsible for this variation ${ }^{[1,6,10,13]}$.

1. Differences in chemical composition:

Commercial Magnesium Stearate actually consists of a mixture of several different fatty acids. A composition consisting of Magnesium Stearate to palmitate in a ratio of $25 \%$ to $75 \%$ respectively is thought to be optimum for "lubricity" and shear properties. But this composition s not usually found in commercial samples.

2. Differences in specific surface area:

Since the lubricating properties of magnesium stearate are related to its ability to coat other particles in a formulation during mixing, samples of a greater surface area should be able to do this more effectively. There is some argument about this however, since it is known that the surface area of magnesium stearate continually changes during blending as a result of its deamination.

3. Differences in crystal structure:

Different crystalline structures have different strengths of attraction between adjacent lamellae thereby affecting its relative ability to delaminate and subsequently coat adjacent particles.

\subsection{Excipients used as lubricants, Antiadherant, or Glidants ${ }^{[15,16]}$.}

Lubricant:

\section{Magnesium Stearate and Calcium Stearate:}

Water Solubility: Insoluble

Conc. Use Range: 0.25 - 1.5\%

Magnesium stearate is the most commonly used and most effective of all lubricants. It is also the most likely to cause compression \& dissolution problems. Concentration, grade and mixing parameters must be carefully controlled. These stearates are alkaline in reaction and cannot be used with some acidic drugs like ASA. Magnesium stearate has good glidant and anti-adherent properties.

\section{Stearic acid:}

Water Solubility: Insoluble Conc. Use Range: 1 $4 \%$ Not as effective a lubricant as Magnesium Stearate. Mixing times not as critical. Incompatibilities include some alkaline salts such as sodium saccharin and sodium phenobarbital.

Hydrogenated Vegetable Oil(Sterotex, Lubritab, Cutina):

Water Solubility: Insoluble Conc. Use Range: 2 $5 \%$ Solid at room temperature, these materials melt at compression pressures and temperatures to impart a lubricating effect.

Hydrogenated Vegetable Oil(Sterotex, Lubritab, Cutina):

Water Solubility: Insoluble

Conc. Use Range: 2 - 5\%

Solid at room temperature, these materials melt at compression pressures and temperatures to impart a lubricating effect.

\section{Mineral Oil:}

Water Solubility: Insoluble

Conc. Use Range: 1 - 3\%

Light mineral oil is an efficient lubricant. But since it must be finely sprayed onto granules and powders to be used, it also can cause noticeable mottling or spotting on tablet surfaces. For these reasons, it is not commonly used anymore. But can still be found in some formulations. 


\section{Polyethylene Glycol 4000 -6000 (PEG):}

Water Solubility: Soluble

Conc. Use Range: 2 - 5\%

Has been used as a water-soluble lubricant for some water soluble and effervescent tablet formulations. Fairly high concentration and low particle size needed to be moderately effective as a lubricant. It has no glidant or anti-adherent properties.

\section{Sodium Lauryl Sulfate (SLS):}

Water Solubility: Soluble

Conc. Use Range: 2 - 3\%

Effective at reducing ejection forces but does not help much for sticking to punch faces. Therefore, it must be used in conjunction with an anti-adherent.

\section{OTHER LUBRICANTS:}

Glyceryl Palmitostearate (Precirol) \& Glyceryl Behenate (Compitrol 888):

Water Solubility: Insoluble

Conc. Use Range: 2 - 5\%

\section{Sodium Benzoate:}

Water Solubility : Soluble

Conc. Use Range: 1 - 4\%

\section{Sodium Stearyl Fumarate (Pruv):}

Water Solubility: Soluble

Conc. Use Range: 0.5 - 2\%

\section{ANTIADHERANTS \& GLIDANTS:}

Talc:

Water Solubility: Insoluble

Conc. Use Range: $1-10 \%$

Not particularly effective on its own as a tablet lubricant or glidant. But very effective with lubricants in the role of an anti-adherent in that it effectively prevents sticking to surfaces. When using talc, it should always be blended into the formulation first followed by the lubricant (i.e. magnesium stearate).

\section{Fumed Silicon Dioxide (Cab-o-sil):}

Water Solubility: Insoluble

Conc. Use Range: As anti-adherent, 1-2\% As glidant, $0.1-0.5 \%$

Fumed Silicon Dioxide has no lubricant properties. It is commercially available as very fine particles (approx. 0.014 microns), which tend to agglomerate into "balls". It functions by coating granules, etc. and reducing interparticulate friction of these thereby improving flow characteristics. For processing, this material must be screened into a batch. However, due to the extremely fine particle size, it should be pre-blended with another component to facilitate screening and distribution. It is an extremely effective glidant at low concentrations, and has antiadherent properties at higher concentrations. However at higher concentrations, flow characteristics may actually be impeded resulting in an increase in weight variation.

Unfortunately the "ideal" lubricant for use in all occasions and with all formulations does not yet exist. However, by understanding how this important class of Excipients functions is solid oral dosage manufacturing; lubricants can be made to work for you and not against you.

\section{CONCLUSION}

Tablet lubricants are those vital ingredients of oral solid dosage form which avoid adhering of granules to die wall. Lubricants also assists tablet to get free of various flaws like amination, sticking, chipping. Mode of action of lubricants follow unlike behavior but here in this review article it has been explained with the help of Surface lubrication and boundary lubrication. Lubricants create a film layer in between die wall and granules. In this review, the basic conditions on lubrication are introduced, in which the relationships between lubrication and friction/adhesion forces are discussed. Then, the application of lubrication in the growth of pharmaceutical products and manufacturing processes is discussed with an emphasis on magnesium stearate. 


\section{REFERENCES}

1. Jarosz, P.J., Parrott, E.L., 1984. Effect of lubricants on tensile strengths of tablets.Drug development and industrial pharmacy 10, 259-273

2. Alderborn, G., 2002. Tablets and compaction.Aulton ME. Pharmaceutics TheScience of Dosage Form Design.

3. John C Carter,Carter Pharmaceutical Consulting, Inc, The Role of Lubricants in Solid Oral Dosage Manufacturing. 2001 2006

4. Rizk S, Guyot J.C, Duru C, Influence of lubricant properties on compression Behavior and drug dissolution rate of scleroglucan hydrophilic matrix, InternationalJournal of Pharmaceutics, 126 (1-2): 57-63, (1995).

5. Levy, G., Gumtow, R.H., 1963. Effect of certain tablet formulation factors ondissolution rate of the active ingredient III. Tablet lubricants. Journal of pharmaceuticalsciences 52,1139-1144

6. Carr, R.L., 1965. Evaluating flow properties of solids.ChemEng 72 .

7. Armstrong, N.A., 2007. Tablet manufacture.Encyclopedia of pharmaceuticaltechnology 6, 3655 .

8. Strickland Jr, W., Nelson, E., Busse, L., Higuchi, T., 1956.The physics of tabletcompression IX.Fundamental aspects of tablet lubrication. Journal of the American Pharmaceutical Association 45, 51-55

9. Sheskey P.J, Robb R.T, Moore R.D, Effects of lubricant level, method of mixing,and duration of mixing on a controlled-release matrix tablet containing hydroxypropylmethylcellulose, Drug lubricant concentration on the adhesion

strength in complexlayer tablets, Drug Development And Industrial Pharmacy., 21 (19):2151-2165, (1995).
10. Doug Nelson, Rebecca $\mathrm{Wu}$, Kate Wymbs. "Effect of Magnesium Stearate on tablet properties.

11. Roblot-Treupel, L., Puisieux, F., 1986. Distribution of magnesium stearate on thesurface of lubricated particles. International journal of pharmaceutics 31 , $131-136$

12. Wang, J., Wen, H., Desai, D., 2010.Lubrication in tablet formulations. EuropeanJournalof Pharmaceutics and Biopharmaceutics 75, 1-15

13. Dietrich P, Bauer-BrandlA, Schubert R. Influence of tableting forces and lubricantconcentration on the adhesion strength in complex layer tablets. Drug Development AndIndustrial Pharmacy 26(7):745-754 (2000).

14. Hamman JH, Tarirai C. Functional excipients. Chemistry Today, 24:57-62 (2006).

15. Raymond C Rowe, Paul J Sheskey, Marian E Quinn. Hand book of pharmaceuticalexciepients. $\quad 6^{\text {th }}$ edition.Washington, USA; RPS publisher; (2009).

16. Niazi, S., 2004. Handbook of Pharmaceutical Manufacturing Formulations: Compressed solid products. CRC Press

17. Dietrich P, Bauer-Brandl A, Schubert R, Influence of tableting forces and Development And Industrial Pharmacy., 26 (7): 745- 754, (2000).

18. Uzunovic A, Vranic E, Effect of magnesium stearate concentration on dissolution properties of ranitidine hydrochloride coated tablets, Bosnian Journal of Basic Medical Sciences, 7 (3): 279-283, (2007).

19. Velasco M.V, Munozruiz A, Monedero M.C, Study of flowability of powders effect of addition of lubricants, Drug Development AndIndustrial Pharmacy., 21 (20): 2385- 2391, (1995).

20. Mollan M.J, Celik M, The effects of lubrication on the compaction and postcompaction properties of directly 
compressible maltodextrins, International Journal of Pharmaceutics, 144 (1): 1-9, (1996).

21. Uzunovic A, Vranic E. Effect of Magnesium Stearate concentration on dissolution properties of ranitidine hydrochloride coated tablets. Bosnian Journal of Basic Medical Sciences7(3):279-283 (2007).

22. Sheskey PJ, Robb RT, Moore RD. Effects of lubricant level, method of mixing, and duration of mixing on a controlled-release matrix tablet containing hydroxypropyl methylcellulose, Drug Development And Industrial Pharmacy.

23. Mollan MJ, Celik M. The effects of lubrication on the compaction and postcompaction properties of directly compressible maltodextrins. International Journal of Pharmaceutics; 144(1):1-9 (1997).

24. Hiremath SN, JithendraPatil, Nagarjuna R, Sway PV. Studies on influence of coexcipients on release rate of diltiazem from carbopol controlled release tablets .Indian Journal of Pharmaceutical Education and Research 43(4):360-364 (2009).

25. Charles E.Carraher,Jr. Seymour/Carraher's Polymer Chemistry; $6^{\text {th }}$ edition. Marcel Dekker; (2005).

26. Faqih, A.M.N., Mehrotra, A., Hammond, S.V., Muzzio, F.J., 2007. Effect of moisture and magnesium stearate concentration on flow properties of cohesive granule materials.International journal of pharmaceutics 336, 338-345

27. Fassihi, A., Kanfer, I., 1986.Effect of compressibility and powder flow properties on tablet weight variation. Drug development and industrial pharmacy 12, 1947-1966

28. Johansson, M., 1985a. Investigations of the mixing time dependence of the lubricating properties of granular and powdered magnesium stearate. Acta pharmaceutica suecica 22,343 . 